\title{
Electrochemical Impedance Spectroscopy Study of the Compressive strength of Concrete
}

\author{
Guilan Tao ${ }^{1,2}$, Congcong Gao $^{2 *}$, Zhaoyang Qiao $^{2}$ \\ ${ }^{1}$ Jiangsu Key Laboratory of Coast Ocean Resources Development and Environment Security, Hohai \\ University, Nanjing 210098, Jiangsu, China \\ ${ }^{2}$ College of Harbour, Coastal and Offshore Engineering, Hohai University, Nanjing 210098, China. \\ *E-mail: gaocongcong@hhu.edu.cn
}

doi: $10.20964 / 2017.12 .38$

Received: 27 August 2017 / Accepted: 23 September 2017 / Published: 12 November 2017

\begin{abstract}
The compactness of cementitious materials is closely related to their mechanical properties and durability. In addition to compressive strength testing, electrochemical impedance spectroscopy (EIS) was applied to measure mortars with different cement contents. The relationships between the compressive strength and EIS results are also discussed. The results suggest that the compressive strength of the samples increased with the impedance and phase angle at low frequency. In particular, most of the compressive strength almost linearly increased with the phase angle when the frequency was lower than $10 \mathrm{~Hz}$. Consequently, compared with the impedance values, the phase angle at low frequency is more suitable for assessing the compressive strength of concrete.
\end{abstract}

Keywords: Concrete; Compressive strength; EIS; Compactness of concrete

\section{FULL TEXT}

(C) 2017 The Authors. Published by ESG (www.electrochemsci.org). This article is an open access article distributed under the terms and conditions of the Creative Commons Attribution license (http://creativecommons.org/licenses/by/4.0/). 